\title{
Educação e Trabalho: As Tramas que Envolvem a TRAJETÓRIA DAS MULHERES NO INSTITUTO FEDERAL DE MATO GRosSo (2008 A 2018)
}

\author{
EDUCATION AND WORK: THE PLOTS THAT AGVE WOMEN'S TRAJECTORY \\ IN THE FEDERAL INSTITUTE OF MATO GROSSO (2008 TO 2018)
}

DOI: 10.23926/RPD.2526-2149.2020.v5.n2.p1278-1297.id707

\section{Silvia Maria dos Santos Stering \\ Doutora e Pós Doutora em \\ Educação (UNESP/Rio \\ Claro-SP) \\ Pós doutora em Educação \\ (UFMT) \\ Professora do Ensino Básico na Secretaria Municipal - \\ SME Cuiabá- MT \\ Pedagoga no Instituto \\ Federal de Mato Grosso \\ (IFMT) \\ silvia.stering@ifmt;edu.br}

\section{Nilce Vieira Campos \\ Ferreira}

Doutora e Pós-Doutora em

Educação (UFU)

Professora Adjunta da

Universidade Federal de

Mato Grosso (UFMT)

Docente do Programa de

Pós-graduação em Educação

(PPGE/UFMT)

nilcevieiraufmt@gmail.com
Resumo: $\mathrm{O}$ artigo aborda o papel da mulher no IFMT, cuja gênese foi eminentemente masculina. Objetivamos analisar a participação da mulher no universo de uma instituição de formação de trabalhadores, desde sua fase de criação em 2008 até 2018, quando completa 10 anos. Partimos da hipótese de que, existe um conflito latente produzido por certo grau de coerção historicamente exercido sobre as mulheres. A investigação historiográfica e bibliográfica tem como fontes a legislação e a imprensa local e oficial, o que permite o registro de parte da memória da instituição. Como toda instituição de ensino, o IFMT não nasceu destituído de um conjunto de interesses. Como resultado tem-se que a abertura para a atuação das mulheres na instituição faz parte da busca por garantia de direitos junto a uma instituição cujo processo de organização, desde os aspectos sociais, culturais, educativos e econômicos, só recentemente ampliou os quadros de atuação às mulheres.

Palavras-chave: História da Educação Feminina. Instituto Federal de Mato Grosso. Educação Profissional e Tecnológica.

\begin{abstract}
The article discusses the role of women in IFMT, whose genesis was eminently male. We aim to analyze the participation of women in the universe of a worker training institution, from its creation phase in 2008 to 2018 , when it turns 10 . We start from the hypothesis that, there is a latent conflict produced by a certain degree of coercion historically exercised on women. Historiographical and bibliographic research is based on legislation and the local and official press, which allows the recording of part of the institution's memory. Like any educational institution, IFMT was not born without a set of interests. As a result, it is clear that the opening to the performance of women in the institution is part of the search for guarantee of rights with an institution whose organization process, from the social, cultural, educational and economic aspects, has only recently expanded the performance frameworks the women.

Keywords: History of Female Education. Federal Institute of Mato Grosso. Professional and Technological Education.
\end{abstract}




\section{INTRODUÇÃO}

O denominado Instituto Federal de Educação, Ciência e Tecnologia de Mato GrossoIFMT, tem sua origem no ano de 2008, coma Lei ${ }^{\circ} 11.892$, de 29 de dezembro de 2008. Embora seja uma instituição recente, tem suas origens no ano de 1909 , mediante Decreto ${ }^{\circ}$ 7.566, de 23 de setembro, expedido pelo Presidente Nilo Peçanha, quando criou as Escolas de Aprendizes e Artífices - EAAMT, destinadas aos "desvalidos da sorte".

Pautamos, portanto, nosso texto na História das Instituições Escolares, uma vez que ocupar-se da memória institucional consiste em analisar e abordar relatos históricos para chegar à compreensão quanto à sua organização e práticas, afinal nas instituições educativas "se entrelaçam acontecimentos de trabalho, questões de poder, vínculos libidinais individuais e grupais, inseridos na cultura recortada de cada organização em particular". (MEZANO, 1998, p.37). Ao estudar a instituição, procuramos investigar a participação das mulheres no IFMT entre os anos de 2008 a 2018, partimos da concepção de que a instituição, ao longo dos anos marcou-se por uma estrutura patriarcal, na qual os homens se sobrepunham numericamente às mulheres.

Nosso recorte temporal deriva do fato de que, no ano de 2008, o então em Centro Federal de Educação Tecnológica de Mato Grosso foi transformado em Instituto Federal de Educação, Ciência e Tecnologia de Mato Grosso, tendo em vista as medidas utilizadas pelo governo federal no período de 2003 a 2006, fase inicial do primeiro mandato do presidente Luiz Inácio lula da Silva, denominada fase de expansão I, para ampliar a política nacional de educação. As decisões para colocar em prática tal ideário foram desencadeadas em diferentes instâncias administrativas: no Ministério da Educação; nas instituições preexistentes que ofertavam a educação profissional; nas instituições recém-criadas e em órgãos locais como prefeituras, em municípios nos quais foram implantados uma unidade de um instituto federal.

A escolha das cidades nas quais foram implantadas novas unidades de Institutos Federais levou em conta três dimensões estabelecidas pelo governo federal para a expansão da rede, a saber: a dimensão social, geográfica e do desenvolvimento, sendo que, a dimensão social visava à universalização de atendimento aos territórios; a dimensão geográfica objetivava a interiorização da oferta pública de educação profissional e o atendimento aos municípios não atendidos por escolas federais; e a dimensão de desenvolvimento visava atender municípios que possuíam arranjos produtivos já identificados.

O Decreto 6.095/2007 foi o primeiro dispositivo legal a tratar do tema da criação dos Institutos Federais de Educação Ciência e Tecnologia, o qual deliberava que o "O Ministério 
da Educação estimulará o processo de reorganização das instituições federais de educação profissional e tecnológica, a fim de que atuem de forma integrada regionalmente" e que esta reorganização se daria pelo modelo de Instituto Federal de Educação, Ciência e Tecnologia. Esta se configura a fase II do projeto de expansão da Rede Federal de Educação Tecnológica.

O IFMT foi criado mediante a integração do Centro Federal de Educação Tecnológica de Cuiabá, do Centro Federal de Educação Tecnológica de Mato Grosso, e da Escola Agrotécnica Federal de Cáceres e de suas respectivas unidades de ensino descentralizadas, a saber: Campo Novo dos Parecis, Bela Vista e Pontes e Lacerda, transformados em campi do Instituto. Encerramos nossa análise em 2018, quando IFMT completa dez anos, pois compreendemos que ao longo desses dez anos a instituição passou por significativas mudanças, principalmente ao considerarmos os espaços ocupados pelas mulheres nessa nova configuração dessa instituição educativa. Podemos dizer que nesses 10 anos houve ganhos substanciais tanto se considerarmos a evolução institucional em relação ao ingresso de mulheres na instituição quanto aos níveis e espaços hierárquicos de atuação que conquistaram.

Objetivamos assim, dar a conhecer a participação da mulher no universo do IFMT, ao longo desses últimos dez anos. Consideramos que, no que diz respeito à questão de gênero no IFMT, existe um conflito latente entre homens e mulheres, com certo grau de coerção exercido sobre o segmento feminino. Ressalvamos que o IFMT, como toda instituição pública não é isento de um conjunto de interesses. Com isso a abertura para a participação das mulheres na instituição também é parte de um longo processo de busca por garantia de direitos junto a uma instituição, cujo processo de organização, tanto nos aspectos sociais, culturais, educativos e econômicos, têm como pressuposto a invisibilidade feminina.

Lembramos Michelle Perrot (1991, p. 185), que nos alertou "da História, muitas vezes a mulher é excluída”. Dessa forma, evidenciamos a presença das mulheres no IFMT, uma vez que elas também assumiram e assumem papel relevante no processo constitutivo dessa instituição federal pública de ensino. Diante do exposto, questionamos: quais espaços de trabalho no IFMT e como eles têm sido ocupados pelas mulheres? O artigo cuja metodologia é histoiográfica e bibliográfica apresenta um histórico da instituição ao longo do tempo, além de abordar a participação feminina na EPT e na nova institucionalização do IFMT. Por último, evidencia as estratégias utilizadas pelas mulheres para ocupar espaços de trabalho na instituição, reivindicando o direito de ter vez e voz na gestão da instituição, de forma participativa e no interior do contexto de equidade e paridade entre os gêneros. 


\section{A GÊnese da InSTITUição: Instituição de EducaÇão Superior, Básica E Profissional, Pluricurricular e multicampi}

Embora a instituição em estudo tenha suas origens em 1909, com a Escola de Aprendizes e Artífices, deteremos nossa análise a partir da Lei n ${ }^{\circ} 11.892$, de 29 de dezembro de 2008, publicada no Diário Oficial em 30 de dezembro de 2008, por meio da qual o presidente Luiz Inácio Lula da Silva criou a Rede Federal de Educação Profissional, Científica e Tecnológica para a oferta de educação profissional e tecnológica nas diferentes modalidades de ensino, Educação Superior, Básica e Profissional, articulando e conhecimentos técnicos e tecnológicos às suas práticas pedagógicas. (BRASIL, 2008). O que aparentemente se se apresentou como uma novidade, no entanto, encontra-se fundamentado na ideia desenvolvida pelo deputado mineiro Fidelis Reis, no ano de 1922, na qual já pretendia instalar Institutos Politécnicos no Brasil.

O projeto apresentado por Fidélis Reis, contudo, foi considerado "o mais radical de quantos projetos já haviam surgido no Brasil a respeito do ensino profissional, pois propunha que o ensino profissionalizante fosse obrigatório no País. Reis lutou pela implantação de mais escolas profissionalizantes, julgando a necessidade da formação de um operariado consciente de sua profissão. (FONSECA, 1961). Afinal, para Reis (1962), a remodelação dos processos de ensino brasileiros criaria" na juventude a vontade realizadora, o espírito construtivo e industrialista, propulsor por excelência do progresso e da riqueza". Com essa concepção propôs as universidades técnicas ou universidades do trabalho.

\footnotetext{
A universidades técnica ou universidade do trabalho, por cuja fundação tanto nos temos batido, seria a cúpula da organização magnífica do novo sistema a inaugurarse. Dentro dele, nos âmbitos d sua vasta estruturação, toda uma seriação de cursos se estabeleceria, vindo das profissões mais elementares, das escolas do trabalho, em todos os municípios, até a cultura técnica superior, nunca se restringindo o homem o horizonte da cultura, o limite do saber. (REIS, 1962, p. 135).
}

Como podemos comprovar no excerto acima, a proposta de Reis já previa um verdadeiro sistema universitário técnico de formação profissional como seria implantado em 2008. Reis destacaria ainda que o ensino profissional como vinha sendo ministrado na República não era mais aceitável, pois dele afastava as elites do país. Para ele a instrução ministrada ao estudante deveria "visar principalmente, a aparelhá-lo para a grande luta do trabalho, fecundo e produtivo". (REIS, 1962, p. 144). O projeto proposto por Fidelis Reis, contudo, foi considerado "verdadeiramente revolucionário", sofrendo forte oposição não foi implantado naqueles anos. (SOARES, 1995, p. 98). 
O fato de a educação do trabalhador nascer sob a égide do governo federal em 1909, é no mínimo curioso. O que leva a considerar às intenções dessa decisão, fazendo-nos acreditar que, desde o princípio da criação da Rede Federal de Ensino, no ano de 1909, suas finalidades tiveram como fundamento o controle por parte do Estado, de maneira clara e objetiva da educação do trabalhador, conforme suas necessidades. Podemos comprovar essa assertiva analisando a normativa que instituiu a Rede de Ensino Profissional no Brasil. Nela é possível ver que o sistema federal de Educação Profissional deveria ofertar o ensino de ofícios, de forma a atender às especificidades da indústria e dos serviços em cada estado, sob a luz das justificativas oficiais, conforme pode-se observar:

Art. $2^{\circ}$ Nas Escolas de aprendizes Artifices, custeadas pela União, se procurará formar operarios e contra-mestres, ministrando-se o ensino pratico e os conhecimentos technicos necessarios aos menores que pretenderem aprender um officio, havendo para isso, até o numero de cinco, as officinas de trabalho manual ou mecanica que forem mais convenientes e necessarias no Estado em que funccionar a escola, consultadas, quanto possivel, as especialidades das industrias locaes. (BRASIL, 1909)

Nessa mesma linha de raciocínio, Luiz Antonio Cunha (2000, p. 65-66) descreveu que seria necessário promover "às classes proletárias os meios de vencer as dificuldades sempre crescentes da luta pela existência", de forma a "habilitar os filhos dos desfavorecidos da fortuna com o indispensável preparo técnico e intelectual, como fazê-los adquirir hábitos de trabalho profícuo". As considerações apresentadas na introdução do Decreto no 7.566, de 1909, demonstravam as motivações vinculadas à criação da Escola de Aprendizes Artífices. Nelas ficam evidentes que o governo brasileiro buscava não só resolver os problemas de ordem econômica e política vigentes naquele tempo histórico, como objetivava a formação da força de trabalho industrial de forma imediatista para atender ao capitalismo que avançava pelo Brasil.

Considerando:

que o augmento constante da população das cidades exige que se facilite às classes proletárias os meios de vencer as dificuldades sempre crescentes da lueta pela existencia: que para isso se torna necessario, não só habilitar os filhos dos desfavorecidos da fortuna com o indispensavel preparo technico e intelectual, como faze-los adquirir habitos de trabalho proficuo, que os afastará da ociosidade ignorante, escola do vício e do crime; que é um dos primeiros deveres do Governo da Republica formar cidadões uteis à Nação. (BRASIL, 1909, p. 01)

Para Nilce Vieira Campos Ferreira (2014, p. 56), a Educação Profissional firmar-se-ia como "um segmento na relação escola-trabalho. Essa discriminação não foi fruto de ideários trabalho e educação, mas de relações sociais concretas, nascidas no campo da produção". Essa foi uma relação que perdurou nos primeiros anos de existência das escolas técnicoprofissionalizantes, fica-nos claro que somente após os anos de 1994, por força da Lei no 8.948, 
de 8 de dezembro é que este cenário é modificado e motiva o processo de expansão e ressignificação da Rede Federal, a partir da organização dos Institutos Federais, por meio do Decreto $n^{\circ} 6.095$, de 24 de abril de 2007 e a posterior Lei de criação, Lei n ${ }^{\circ} 11.892$ de 29 de dezembro de 2008.

Dando continuidade à expansão da Rede Federal, o governo Lula lançou o Plano de Expansão da RFEPCT, cuja operacionalização foi dividida em Fase I e Fase II, em que foi lançada a primeira fase do Plano de Expansão da Rede Federal no ano de 2005 com a construção de 60 novas unidades de ensino pelo Governo Federal. Neste mesmo ano, o CEFET do Paraná passou a ser Universidade Tecnológica Federal do Paraná através da lei n ${ }^{\circ} 11.184$, de 7 de outubro de 2005. Fazem parte da I fase da expansão, o Campus Cuiabá - Octayde Jorge da Silva, São Vicente, Cáceres, Bela Vista, Pontes e Lacerda e Campo Novo do Parecis.

Em 2007, aconteceu o lançamento da segunda fase do Plano de Expansão da RFEPCT, tendo como meta entregar à população mais 154 novas unidades, perfazendo um total de 356 unidades em 321 municípios atendidos até o final de 2010, cobrindo todas as regiões do país, oferecendo cursos de qualificação, de ensino técnico, superior e de pós-graduação, sintonizados com as necessidades de desenvolvimento local e regional. Como parte da II fase da expansão do IFMT foram criados os Campus Sorriso, Barra do Garças, Confresa, Juína e Rondonópolis

No primeiro mandato da Presidente Dilma Rousseff, a partir de 2010, foi garantida não só a conclusão das metas previstas para o período entre 2003 e 2010, como também a continuidade da expansão da Rede Federal. É neste contexto que na III fase da expansão foram criados o Campus Várzea Grande, Alta Floresta, Primavera do Leste, e os Campi avançados de Diamantino, Guarantã do Norte, Lucas do Rio Verde, Sinop e Tangará da Serra.

$\mathrm{Na}$ atualidade, o IFMT, enquanto parte da Rede Federal de Educação Profissional e Tecnológica conta com 14 (quatorze) campi em funcionamento, sendo composto por: Alta Floresta, Barra do Garças, Cáceres, Campo Novo do Parecis, Confresa, Cuiabá - Octayde Jorge da Silva, Cuiabá - Bela Vista, Juína, Pontes e Lacerda, Primavera do Leste, Rondonópolis, São Vicente, Sorriso e Várzea Grande. Possui ainda cinco campi avançados instalados nos municípios de Diamantino, Guarantã do Norte, Lucas do Rio Verde, Sinop e Tangará da Serra.

Como resultado visível das intenções com a criação dos Institutos Federais, no ano de 2010, o campus Confresa-MT foi fundado como um marco significativo para a Microrregião do Norte-Araguaia, pois Confresa é um município que tem $83 \%$ do território ocupado por assentamentos oriundos da reforma agrária. Ali residem cerca de cinco mil famílias assentadas, totalizando 60 assentamentos registrados pela Superintendência Regional do Incra e pela 
Prefeitura Municipal. Um ano após a criação do IFMT, o jornal Olhar Direto descreveu os cursos que o IFMT ofertava no estado mato-grossense.

Em seu primeiro ano de vida o IFMT foi o responsável por levar desenvolvimento às regiões onde atua no Mato Grosso. Com oito campi e três núcleos avançados o IFMT oferece 38 cursos nas áreas de bacharelado, licenciatura, tecnologia, cursos técnicos de nível médio (integrados e subsequentes) e cursos de pós-graduação (lato sensu). Para 2010 o IFMT espera mais de 13 mil novos alunos espalhados nas cidades de Mato Grosso onde faz presença através de seus campi, núcleos avançados e através da Universidade Aberta do Brasil (UAB). E para atender a essa demanda nomeou na última quarta-feira (23) mais 97 professores, o que totaliza um quadro de 513 docentes. Mas o IFMT ainda está crescendo. Com a parceria da Prefeitura de Poconé, o IFMT está em processo de criação de mais um núcleo avançado na região pantaneira e está terminando a construção de mais dois campi: em Barra do Garças e Rondonópolis. Dessa forma o IFMT pretende alcançar todas as regiões do Estado de Mato Grosso. (OLHAR DIRETO, 2009).

Com status de universidade, os Institutos Federais tornaram-se instituições de educação superior, básica e profissional, pluricurriculares e multicampi, especializados na oferta de educação profissional e tecnológica nas diferentes modalidades de ensino, com base na conjugação de conhecimentos técnicos e tecnológicos e práticas pedagógicas específicas. (BRASIL, 2008). Os Institutos Federais assumiram a responsabilidade de ofertar educação básica e tecnológica, além da formação em nível superior, pós-graduação latu e stricto sensu, a ainda a Formação Inicial e Continuada -FIC. Consoante o artigo $6^{\circ}$ da lei $n^{\circ} 11.892$, de 29 de dezembro de 2008 que instituiu a Rede Federal de Educação Profissional, Científica e Tecnológica, Seção II, Das Finalidades e Características dos Institutos Federais, no artigo $6^{\circ}$ determinou a finalidade dessas instituições educativas.

Art. $6^{\circ}$ Os Institutos Federais têm por finalidades e características: I - ofertar educação profissional e tecnológica, em todos os seus níveis e modalidades, formando e qualificando cidadãos com vistas na atuação profissional nos diversos setores da economia, com ênfase no desenvolvimento socioeconômico local, regional e nacional;II - desenvolver a educação profissional e tecnológica como processo educativo e investigativo de geração e adaptação de soluções técnicas e tecnológicas às demandas sociais e peculiaridades regionais; III - promover a integração e a verticalização da educação básica à educação profissional e educação superior, otimizando a infraestrutura física, os quadros de pessoal e os recursos de gestão; IV orientar sua oferta formativa em benefício da consolidação e fortalecimento dos arranjos produtivos, sociais e culturais locais, identificados com base no mapeamento das potencialidades de desenvolvimento socioeconômico e cultural no âmbito de atuação do Instituto Federal;V - constituir-se em centro de excelência na oferta do ensino de ciências, em geral, e de ciências aplicadas, em particular, estimulando o desenvolvimento de espírito crítico, voltado à investigação empírica; VI - qualificarse como centro de referência no apoio à oferta do ensino de ciências nas instituições públicas de ensino, oferecendo capacitação técnica e atualização pedagógica aos docentes das redes públicas de ensino;VII - desenvolver programas de extensão e de divulgação científica e tecnológica;VIII - realizar e estimular a pesquisa aplicada, a produção cultural, o empreendedorismo, o cooperativismo e o desenvolvimento científico e tecnológico;IX - promover a produção, o desenvolvimento e a transferência de tecnologias sociais, notadamente as voltadas à preservação do meio ambiente. (BRASIL, 2008). 
Nesta direção, o IFMT a partir de 2008 se configurou como multicampi. A reitoria foi instalada em Cuiabá, composta com o seguinte organograma (Figura 1).

Figura 1 - Organograma básico de um instituto federal (lei N $\square$ 11.892/ 2008)

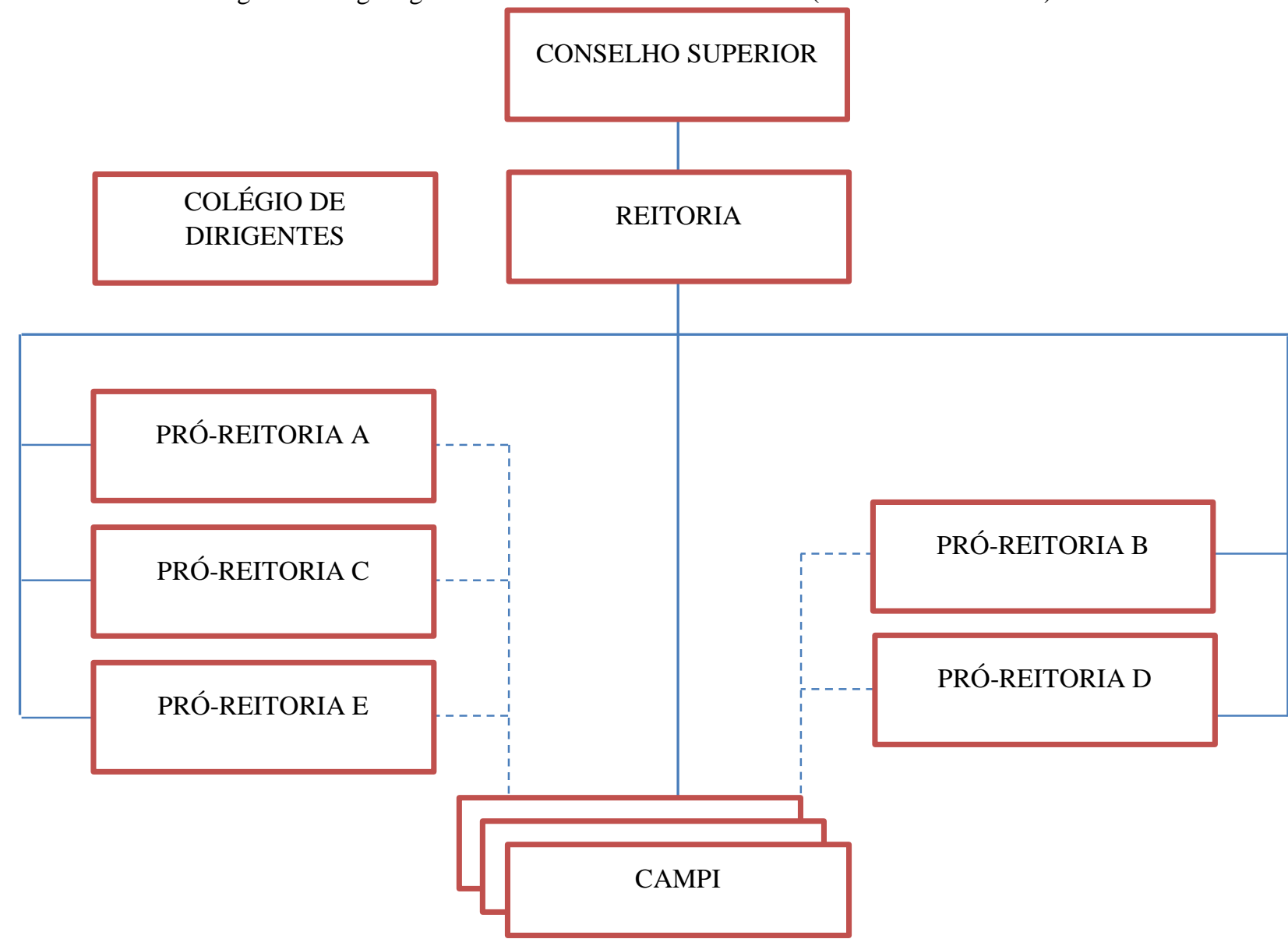

Fonte: Elaborado pela autora (2018).

Como podemos apontar, o IFMT se constituiu como uma instituição de ensino que oferta cursos em várias localidades do estado de Mato Grosso, sendo no total 119 cursos distribuídos em: Concomitante ao Ensino Médio - Integrado ao Ensino Médio - Proeja, Subsequentes ou Pós Médio Superiores. Diante do contexto apresentado, cabe questionar: Como as mulheres se colocam no âmbito da instituição? Como participaram e se movimentaram no âmbito dessas mudanças sofridas pelo IFMT ao longo dos anos? Nossa percepção é a de que esse registro também é uma forma de memória do IFMT, pois conforme Justino Magalhães,

\footnotetext{
A história das instituições educativas constituiu um domínio do conhecimento em que se tem operado uma profunda alteração metodológica, uma vez que há uma narrativa de natureza cronística e memorialista, que informa as representações e os relatos orais dos atores se procura contrapor uma base de informação arquivística, sob uma heurística e uma hermenêutica complexa, problematizantes e centradas na instituição educativa como totalidade em organização e desenvolvimento. Uma história construída(s) da(s) memórias(s) para o arquivo e do arquivo para a memória, intentando uma síntese multidimensional que traduza um itinerário pedagógico, uma
} 
identidade histórica, uma realidade em evolução, um projeto pedagógico (MAGALHÃES, 1999, p.61).

Partindo de ideia de Justino Magalhães (1999), a memória busca explicar as relações de hierarquia e valores tanto entre as coisas como entre as pessoas, pois tudo o que nela acontece não é em vão nem tão pouco se perde, às vezes permanece ou se transforma.

\section{O Protagonismo Feminino no IFMT}

Ao considerarmos a sociedade brasileira como de base patriarcal, podemos observar que a educação destinada às mulheres sempre esteve vinculada aos papéis sociais imputados a elas, muito embora quase sempre essa história tenha sido desconsiderada ou pouco estudada. Essa realidade foi descrita por Michele Perrot.

[...] cada sexo tem sua função, seus papéis, suas tarefas, seus espaços, seu lugar quase predeterminados, até em seus detalhes . Paralelamente existe um discurso dos ofícios que faz a linguagem do trabalho uma das mais sexuadas possíveis. (PERROT 2007, p.178).

Para Perrot (1991), durante o século XIX e início do XX existia uma "harmoniosa" divisão sexual, na qual homens e mulheres tinham bem definidos sua função, papel, tarefa e espaços pré-determinados, o que determinava os ofícios aceitáveis a cada gênero. Para os homens eram destinados os trabalhos com a madeira e os metais, e à mulher, os afazeres ligados ao cuidado com a família e o trabalho com os tecidos. Com isso os fazeres femininos circunscreviam-se ao cumprimento das atividades "naturais" de sua condição feminina: aprovisionar um espaço doméstico organizado e adequado no que se refere à manutenção da estrutura física, a fim de melhor cuidar dos filhos e familiares. Enfim, as notabilidades femininas, como descrito, por Guacira Lopes Louro e Dagmar Meyer no artigo intitulado "A escolarização do doméstico. A construção de uma escola técnica feminina (1946-1970)", cujo objetivo era a formação da mulher como "profissional hábil e competente e excelente dona de casa" (LOURO e MEYER 1993 p.46).

À formação das mulheres cabia assim propiciar o acesso à atividades relativas à prática da costura, limpeza, às lides culinárias, à alimentação das crianças, enfim, formar uma mulher que deveria ser boa mãe e esposa, portadora de moral sólida e princípios cristãos, condições imprescindíveis para se encontrar um bom partido e se casar, ou como também ressaltado por Ferreira (2014, p. 185) "o destino que o conservadorismo apontava era o das notabilidades femininas tradicionais: a cama e o fogão, as prendas do lar".

Portanto, de certo modo, a educação profissional durante muitos anos para as mulheres destinou-se a formar as mulheres para a nobre missão fundamental da mulher, que é de esposa 
e mãe. (LOURO e MEYER, 1993 p.56). Nessa direção, no início do século XX, as mulheres trabalhadoras praticamente não conseguiam acesso à educação profissional em Mato Grosso. A Escola de Aprendizes Artífices de Mato Grosso - EAAMT, origem do IFMT, desde sua criação, no ano de 1909 até 1971 realizava a oferta de cursos exclusivamente para alunos do sexo masculino, o evidencia o caráter excludente da instituição.

Mesmo com o advento do ensino industrial em substituição ao ensino de artífices, a Escola Industrial de Cuiabá, depois nominada Escola Técnica Federal de Mato Grosso, continuou na fixidez de ofertar vagas apenas a alunos do sexo masculino. A cultura local, cuiabana, tinha o sexo feminino como dependente do masculino, em subordinação explícita. Parte dessa letargia no processo de admissão de mulheres naquele estabelecimento de ensino pode ser explicada pelos cursos técnicos promoverem a habilitação para atividades ligadas ao trabalho, até então consideradas exclusivas do sexo masculino e, em parte, porque o parque industrial mato-grossense não existia como expressão econômica antes da abertura das novas fronteiras agrícolas, do chamado "milagre econômico" do final da década de 1960, e até a crise do petróleo em 1973, que ligou Mato Grosso à estrutura produtiva nacional.

Um olhar focado na gestão da instituição pode esclarecer o atraso na oferta de vagas às mulheres. Orlando Nigro dirigiu a instituição ao longo de quase25 anos, de 1941 a 1966, período em que ocorreu a Reforma Capanema, decisiva para que as escolas da rede federal assumissem o ensino técnico e propusessem vagas às mulheres. A permanência de dirigentes por muito tempo na direção da instituição pode ter colaborado para que nenhuma "ousadia" tenha sido tentada. Outro fato significativo foi a rede de parentela que se formou no corpo administrativo e docente da EAAMT (KUNZE, 2006).

Somente a partir de 1972 a instituição passou a aceitar a matrícula de mulheres em seus cursos, tendo em vista que, no ano de 1971 com a promulgação da Lei 5.692/71 a oferta da ETFMT passou por uma distinção de nível em razão da oferta exclusiva do ensino técnico de nível médio, no ano de 1972, ano em que é possibilitada a matrícula para mulheres em quatro cursos técnicos: Estradas, Edificações, Eletrotécnica e Secretariado. Inexiste razão explícita para que a oferta de vagas às mulheres só viesse a acontecer a partir de 1972. Contudo, um olhar para a cultura local e nacional, não deixa dúvida quanto à esfera de participação da mulher brasileira na primeira metade do século XX, quase que restrita ao âmbito doméstico nas classes menos favorecidas e mera coadjuvante nas classes dominantes.

Em relação às profissionais que atuaram no IFMT, Kunze (2009) relatou que a primeira professora a lecionar na EAAMT foi Ana Izabel de Campos Barros que assumiu o cargo de 
professora do curso noturno primário, que funcionava das $17 \mathrm{~h}$ às $20 \mathrm{~h}$, até o ano de 1911 , e que depois passou a denominar-se curso primário, funcionando das 7 h30 às 11h30. Barros foi nomeada no dia 18 de dezembro de 1909, pelo Ministério da Agricultura, Indústria e Comércio, órgão ao qual a escola estava vinculada, tendo sido empossada no dia 24 de janeiro de 1910. Ao longo dos seus trinta anos de trabalho na EAAMT, a professora Ana Izabel, além de lecionar, por diversas vezes desempenhou a atividade de escriturária substituta.

Ainda Kunze (2009) descreveu que ela, mesmo sendo indicada pelo diretor, Pedro Gardés, no momento de sua posse precisou da apresentação de autorização do pai e atestado de boa conduta emitido por uma autoridade policial. Ela tinha apenas o curso primário e não era normalista, conforme exigia o regulamento escolar para essa função profissional. Para Elisabeth Madureira Siqueira (2000) esse era um dos maiores problemas com o qual Mato Grosso se deparava: a falta de professores formados para o magistério. A administração pública argumentava que semelhante realidade era consequência da falta de investimento e efetivação de uma Escola Normal, várias vezes aberta e encerrada.

Kunze (2009), esclarece que, além de Ana Izabel de Campos Barros, professora primária pertencente ao quadro efetivo da escola, a EAAMT contou com a colaboração profissional de outras docentes, como Elvira Barros Moreira que assumiu a cadeira de adjunta de professora primária no quadro temporário, nos anos de 1912 a 1915. Semelhante cargo foi exercido, no ano de 1933, também por Elza Pires de Arruda.

Foi somente no ano de 1938 que a primeira normalista adentrou EAAMT. Olga Corrêa de Almeida atuou como coadjuvante do ensino de $3^{\mathrm{a}}$ classe, nomenclatura dada à adjunta de professora primária até 1940, quando se mudou para o Rio de Janeiro. Em sua substituição assumiu a profa. Maria de Lara Pinto, diplomada no curso secundário e que, em 1941, assumiu as aulas dos cursos noturnos. (KUNZE, 2009).

A partir de 1938, mais mulheres adentraram o quadro do IFMT e construíram história. Segundo dados do GDRH CEFET (2007), levantados por Figueiredo (2008), no ano de 1970 eram professoras da ETFMT Edna Albuquerque Affi e Judith Guimarães Cardoso, ambas se tornariam anos depois, diretoras da escola. As professoras eram parte da equipe pedagógica que deliberava sobre a política da educação na esfera da ETFMT. Elas foram personagens decisivas na emergência feminina que se deu a partir de 1972 no cenário da instituição.

A participação das mulheres no corpo docente, ainda que tímida, sempre existiu no CEFETMT desde a sua fundação. Na Escola de Aprendizes e Artífices, posteriormente ginásios industriais e técnicos de nível médio apresentavam como partes dos seus currículos formativos 
o que se denomina de formação geral e profissional nos cursos técnicos, até a reforma da educação profissional em 1997. Em geral, as mulheres atuavam nas disciplinas voltadas para a formação geral.

Em janeiro do ano de 2007, o CEFETMT contava no seu quadro docente com 16 doutores, 70 mestres, 135 especialistas e 36 graduados, sendo que as mulheres com mestrado eram em maior número $38,54,28 \%$, e minoria entre os doutores e especialistas. A explicação para o fato da maioria das mulheres serem mestras, está ligada às áreas educacionais. As professoras com mestrado atuavam na área Propedêutica, eminentemente feminina, e Química, em função de sua gênese a partir da reunião dos professores com licenciatura em química, a maioria feminina, e os bacharéis em química e engenharia. Parte significativa dos mestrados nessas áreas são em educação, realizados na Universidade Federal de Mato Grosso UFMT. (FIGUEIREDO, 2008).

É possível constatar a evolução do número de docentes entre 1984 e 2007 em relação ao currículo ministrado - formação geral e profissional. Em todo o CEFETMT o aumento foi de $1,36 \%$ de mulheres e no caso do currículo da formação geral diminuiu a proporção de mulheres em $1,07 \%$. O acréscimo de mulheres no CEFETMT é explicado pelo aumento de professoras no currículo profissional, docentes que ministram aulas de matérias ou disciplinas exclusivamente técnicas, e uma queda sutil na formação geral. O currículo profissional teve aumento significativo, se comparado com o CEFETMT, de 4,73\%. Essa ampliação condiz com a evolução da oferta de cursos nas áreas educacionais diversas da Construção Civil e Eletroeletrônica e Serviços como Informática e Química que não existiam no ano de 1984. (FIGUEIREDO, 2008).

Pode-se perceber também a evolução do corpo docente por área e sexo, o que auxilia no desvelar da visibilidade feminina no quadro docente do CEFETMT. Houve aumento tanto nas áreas educacionais da Construção Civil quanto da Eletro- eletrônica e um declínio quase insignificante da área de Serviços. Ainda que o quadro nas áreas mais masculinas do CEFETMT tenha melhorado, continua pequena a participação de mulheres nas áreas de Eletro-eletrônica, 9,80\%, e Construção Civil, 20\%. A visibilidade feminina aumentou com o advento das novas áreas educacionais: Informática com $40 \%$ de mulheres e Química com $45 \%$.

Até o ano de 1971 inexistia professoras para as disciplinas técnicas ou profissionalizantes. Mesmo depois da existência de professoras para essa especificidade, o a participação feminina era pequena. Conforme os dados do GDRH - CEFETMT (2007), levando em conta as áreas de educacionais a proporção de mulheres em relação aos homens era pouco 
significativa, somente cinco eram engenheiras entre as 14 professoras, as demais compunham o quadro do curso de Secretariado. As engenheiras professoras, lecionavam as disciplinas introdutórias como Desenho Básico; as disciplinas consideradas mais tecnológicas como as de cálculo estrutural e de projetos eram destinadas aos engenheiros professores.

O emprego público, na primeira metade do século XX, era preferencialmente masculino, fato que certamente conduziu a instituição a não ofertar vaga às mulheres, situação que levaria à contratação de mulheres como docentes, visto que ser professora correspondia à reprodução das atividades domésticas no tratamento maternal das crianças. Além disso, o imperativo dos mestres e contramestres do antigo ensino de artífices foi decisivo para que, somente 25 anos depois do advento dos cursos técnicos para a rede federal, fossem ofertadas vagas às mulheres na então ETFMT.

\section{A Participação da Mulheres e sua relação com o trabalho no ifMT- CONQUISTAS RECENTES.}

$\mathrm{Na}$ busca por evidenciar o percurso percorrido pelas mulheres para conquistar espaço de participação no IFMT, frente ao lento processo de transformação da identidade da instituição, destacamos o aumento significativo do número de mulheres e sua participação na gestão da instituição. Segundo números extraídos da base de dados do governo federal, o Sistema Unificado de Administração Pública - SUAP, atualmente, o IFMT possui 1.818 servidores em todo o estado, sendo: 761 mulheres, dentre as quais 358 docentes e 403 técnicas.

Temos como exemplo de atuação feminina a profa. Tereza Irene Ribeiro de Carvalho Malheiros, docente titular do Curso de Eletrotécnica, tendo sido aluna da primeira turma do curso, no ano de 1971. Concluiu estes estudos no ano de 1975 e desde então permaneceu na instituição como docente, atendendo ao convite do Coronel Octayde Jorge da Silva, então Diretor da instituição. Professora Doctora of Philosophy -PhD do IFMT - Campus Cuiabá, com 30 anos de atuação docente, foi a primeira professora a ascender à classe de titular no IFMT. (RH do IFMT, 2018).

No Brasil, embora o magistério, especialmente o de ensino fundamental, tenha sido por muito tempo um espaço feminino, no tocante à docência em educação profissional a presença das mulheres foi perpassada por grande resistência. Considerando a sociedade brasileira como machista, a realidade não poderia ser diferente, já que as mulheres não poderiam ensinar aquilo que não sabiam fazer, justificando a base biológica de exclusão do sexo feminino, conforme afirma Michelle Perrot. 
o velho discurso retoma no século XIX um novo vigor, apoiando-se nas descobertas da medicina e da biologia. É um discurso naturalista, que insiste na existência de duas 'espécies' com qualidades e aptidões particulares. Aos homens, o cérebro (muito mais importante do que o falo), a inteligência, a razão lúcida, a capacidade de decisão. Às mulheres, o coração, a sensibilidade, os sentimentos" (PERROT, 1998 p.177).

Primeira doutora da instituição, Tereza Irene Ribeiro de Carvalho Malheiros concluiu o doutoramento no ano de 1994, pela Universidade de New Castle, na Inglaterra. Nádia Cuiabano Kunze é Técnica em Assuntos Educacionais, datando de dezembro de 1984seuvínculo inicial com a Escola Técnica Federal de Mato Grosso, quando prestou o exame de seleção para ingresso no Curso Técnico de Secretariado. Aprovada, efetuou a matrícula e iniciou os estudos em 1985, finalizando-os em 1987. Mesmo tendo concluído todas as disciplinas do curso de $2^{\mathrm{a}}$ grau técnico, Nádia optou por não fazer o estágio supervisionado, recebendo o título de Auxiliar Técnico em Secretariado, conforme Lei n. 7.044, de 18.10.1982, e pôde prosseguir nos estudos de nível superior, concluindo, assim, o Curso de Pedagogia na Universidade Federal de Mato Grosso em 1991.

Foi aprovada em concurso público no Ministério da Educação e do Desporto para o cargo de Técnica em Assuntos Educacionais de Nível Superior, em 1984, exercendo as atividades de analista de financiamento de projetos educacionais municipais e estaduais e de planejamento de políticas nacionais da educação, com lotação na Delegacia do MEC em Mato Grosso. Com a reforma administrativa implementada pelo governo de FHC, a DEMEC-MT foi extinta em 1998, e os servidores que não optaram pelo Plano de Demissão Voluntária (PDV) tiveram que solicitar vinculação funcional a outro órgão do poder executivo federal.

Assim, Nádia Cuiabano Kunze solicitou enquadramento na ETFMT e, desde então, desenvolve, dentre outras, as seguintes atividades: Gestão escolar - Coordenação de pesquisa, coordenação de produção e desenvolvimento, coordenação de Minter, coordenação de pósgraduação; Assessoramento nas atividades de ensino, pesquisa e extensão; Planejamento, análise, supervisão, orientação e avaliação do processo educativo; Elaboração de normativas e regulamentos em comissões institucionais; Organização, elaboração e execução de periódico e eventos científicos institucionais; Pesquisas e estudos científicos sobre EPT, história da instituição escolar e da educação profissional, arquivos escolares, memória e identidade institucional; Publicação de resultados de pesquisas científicas; Capacitação continuada -cursos de aperfeiçoamento, atualização, pós-graduação: mestrado e doutorado; Membro de bancas avaliadoras de concursos e de trabalhos de conclusão de cursos-TCC, Monografias, Dissertações, teses; Parecerista ad hoc de periódicos e eventos científicos e de agências de fomento à projetos científicos etc. 
A trajetória de Kunze vem ao encontro do que Carla Cabral e Walter Bazzo (2005) destacam quanto ao acesso à leitura e à escrita, que, em contexto histórico, de meados do século XVII, foi alterando o lugar da mulher nas sociedades e, consequentemente, sua participação em carreiras científicas e tecnológicas. Fica evidente que, na atualidade, o acesso das mulheres a todas as carreiras é livre, contudo, ainda existem inúmeras barreiras que restringem sua participação na produção do conhecimento científico e tecnológico, restrição tanto hierárquica quanto territorial, num universo majoritariamente masculino, não só no que se refere à pesquisa, mas também ao trabalho.

Nadja Gomes Machado, servidora integrante do quadro de professores do Instituto Federal de Mato Grosso (IFMT), Campus Cuiabá - Bela Vista, faz parte do programa de Bolsa Produtividade em Pesquisa (Bolsa PQ), oferecido pelo Conselho Nacional de Desenvolvimento Científico e Tecnológico (CNPq), vinculado ao Ministério da Ciência e Tecnologia. Semelhante bolsa é destinada aos pesquisadores que se destacam, dentre os profissionais de uma mesma área, na produção científica. A proposta do programa é conceder esse apoio aos pesquisadores de todas as áreas do conhecimento, enquanto valorização e incentivo à produção científica. $\mathrm{O}$ título concedido à professora reflete também nas produções científicas executadas no âmbito do IFMT - Bela Vista, colocando esse bairro de Cuiabá como referência no quadro de docentes, entre os Campi de Mato Grosso: “As bolsas de produtividade oferecidas pelo CNPq configuram como um termômetro para a qualidade do profissional, programas de pós-graduação e também para a Instituição de Ensino" (ASCOM,16/01/2018).

Professora do Campus do IFMT - Bela Vista há 10 anos, coordena o laboratório de Biologia da Conservação (Labic), que tem foco nos estudos relacionados à compreensão do funcionamento, estrutura e dinâmica de ecossistemas naturais e modificados pelo homem. Ela é Graduada em Ciências Biológicas (2004), Mestre em Ecologia e Conservação da Biodiversidade (2007) e Doutora em Física Ambiental (2013) pela Universidade Federal de Mato Grosso (UFMT), fez Estágio Pós-Doutoral em Ciências Ambientais na Utah State University (2014-2015). $\quad$ A carreira da docente em questão foge a lógica defendida por Cabral e Bazzo (2005, p. 3), que afirmam que as mulheres, historicamente, foram afastadas do círculo criativo e da liderança da produção científica e tecnológica.

$\mathrm{Na}$ atual gestão, dentre os 19 campi, o IFMT conta com 3 gestoras. O campus Várzea Grande, com a Professora Sandra Maria de Lima, mediante Portaria $n^{\circ} 871$ D.OU, de 20/04/17, que é graduada em Engenharia Civil pela Escola de Engenharia de Lins, no ano de 1991. Especialista em Engenharia Ambiental pela Faculdade de Saúde Pública da USP, no ano de 
1997, mestra em 2006 e doutora em 2008 em Engenharia Civil, pela Escola de Engenharia de São Carlos - USP, área de concentração Engenharia de Estruturas. De acordo com Schiebinger (2001, p. 61), as mulheres “[...] com frequência prosperavam em campos, como a física e a matemática, considerados, hoje, especialmente resistentes às incursões femininas”. A trajetória de Sandra evidencia tal perspectiva.

Diretora do Campus Rondonópolis, por Portaria n ${ }^{\circ}$ 862, de 19 de abril de 2017, o qual oferta quatro cursos de Ensino Médio Integrado e três de Ensino Superior, além de cursos de extensão, tendo, assim, em torno de 700 alunos e 130 servidores, a saber: Laura Caroline Ayoama Barbosa, bacharel em Biblioteconomia e Documentação pela UFMT, com especialização em Gestão da Educação Profissional e Tecnológica, também pela UFMT, e o título de Mestre em Ciência Política, pela UFPE.

É crescente o aumento do número de mulheres e seu protagonismo no IFMT, assim como no mercado de trabalho. Contudo, há que se considerar a existência de uma dupla dimensão, pois "de um lado a conquista de bons empregos, o acesso a carreiras e profissões de prestígio e a cargos de gerência, e mesmo de diretoria, por parte de mulheres escolarizadas, e de outro o predomínio do trabalho feminino em atividades precárias e informais". (BRUSCHINI; LOMBARDI, 2006, p. 45).

Gilma Silva Chitarra, Portaria $\mathrm{n}^{\circ} 870$, de 19.04.2017, é diretora do campus do IFMT Sinop. A professora é graduada em Agronomia pela Faculdade de Agronomia e Zootecnia Manoel Carlos Gonçalves, no ano de 1984, mestra em Agronomia em Fitopatologia, pela Universidade Federal de Lavras, no ano de 1996, e doutora em Nutrição, Tecnologia e Biotecnologia de Alimentos - Wageningen University And Research Centre, no ano de 2003, revalidado pela Universidade de Lavras - MG, Doutorado em Agronomia/Fitopatologia. É professora de Mestrado em Ciência e Tecnologia de Alimentos do IFMT - Campus Bela Vista.

É perceptível a conquista do espaço pelas mulheres no IFMT, assim como são evidentes as transformações que envolvem sua participação na sociedade brasileira, transformações que as mulheres no IFMT não estão imunes, o que nos leva a concordar com Perrot (2012, p. 15), ao afirmar que "a história das mulheres mudou".

Em seus objetos, em seus pontos de vista. Partiu de uma história do corpo e dos papéis desempenhados na vida, privada para chegar a uma história das mulheres no espaço público da cidade, do trabalho, da política, da guerra, da criação. Partiu de uma história das mulheres vítimas para chegar a uma história das mulheres ativas, nas múltiplas interações que provocam a mudança. (PERROT, 2007, p. 15). 
A chegada das mulheres ao espaço público se deu por meio de sua entrada na educação básica, sendo que o ensino era considerado enquanto forma de fortalecer os aprendizados inerentes às suas atribuições na esfera domésticas, limitando o seu conhecimento em outras áreas. Posteriormente, sua inserção no ensino superior e a entrada no mercado de trabalho foram influenciadas por suas obrigações domésticas. Tal situação levou as mulheres a se concentrar em áreas voltadas especificamente para o cuidar e o educar, ficando a área tecnológica fora desta intenção. Contemporaneamente, assistimos as mulheres atuar nas mais diversas áreas, incluindo as de ciência e tecnologia, o que as coloca, mesmo que minoritariamente, num campo de trabalho que, até poucos anos atrás, estava restrito aos homens.

\section{Algumas Considerações}

Na busca por abordar o papel da mulher no IFMT, cuja gênese foi eminentemente masculina, o artigo objetivou analisar a participação da mulher no universo de uma instituição de formação de trabalhadores, desde sua fase de criação em 2008 até 2018, quando completa 10 anos. Se por um lado admite-se que uma educação a serviço do mundo do capital possui sua função desvirtuada, cumprindo, portanto, uma disfunção, contudo, sem que seja possível prescindir de sua importância, talvez a finalidade dos Institutos Federais esteja a serviço da ideologia da divisão de forças, e não ao contrário, razão pela qual eles possuem uma reitoria localizada distante dos campi pulverizados em todo o estado, como é o caso de Mato Grosso.

O objetivo desta investigação foi o de dar a conhecer a participação da mulher no IFMT, tendo por foco os dez anos de existência da nova institucionalização, sob esta nomenclatura, tendo sido as hipóteses, levantadas inicialmente, confirmadas plenamente. A educação profissional Brasil nasceu perpassada pela dualidade, cuja marca é a distribuição de renda desigual que se fortalece na desigual distribuição do conhecimento o que também afeta diretamente as mulheres. Ao percorrermos a trajetória feminina na busca por espaço de participação na EPT, nos últimos dez anos no IFMT, é possível visualizar que o início das atividades intelectuais da mulher na instituição, aconteceram com o nascimento da modernidade, e sua inclusão social se deu sob o signo da instrumentalização do sexo.

O século XIX foi determinante para a manutenção da cultura patriarcalista no Brasil, na qual a mulher tinha que prestar contas ao pai, ao marido, enfim, a toda a sociedade e, também ao Estado. O movimento para sua inicial emancipação ocorreu no campo educacional, considerado como segundo lar, e a professora qualificada pelo "instinto" maternal, tão suave e severa quanto na educação de seus próprios filhos. Uma vez que a participação da mulher no 
plano social exigiu treinamento e exercício constante, ainda que necessitasse de apoio e vigilância ao longo de décadas, a entrada da mulher na EPT se deu na perspectiva de sua contribuição no processo de modernização do país, em que a educação de base era promovida pelo Estado, e de forma agradável e facilitada, visto que desenvolvida por mulheres. Conforme evidenciado neste artigo, a conquista do espaço para a participação da mulher na instituição se deu pela via do conhecimento científico, cada vez mais presente na no cotidiano das docentes e técnicas que fizeram parte do quadro de servidores da instituição. $\mathrm{Na}$ atualidade, muitas pesquisadoras do IFMT são destaque em produtividade e inovação, em suas áreas de pesquisa. Elas trazem olhares diferenciados para o fazer científico e isso beneficia a produção de conhecimento. Nessa medida, a ciência pode ser um caminho para o empoderamento feminino.

A instituição tem exemplo de mulheres que, além de buscar soluções tecnológicas para os setores produtivos, estão ajudando a aumentar o poder desse segmento e a construção da igualdade de gênero em outros espaços sociais, tendo em vista que é importante trazer visibilidade para o trabalho e para os saberes produzidos por mulheres, numa perspectiva que vá além dos espaços acadêmicos. Não basta somente fazer ciência, atuar na academia, mas contribuir de forma incisiva com o debate sobre sua condição, para que haja reconhecimento do trabalho das mulheres. Ao nosso ver, para que os trabalhos de mulheres sejam mais valorizados na instituição e fora dela se faz necessário garantir que elas tenham oportunidade para realizá-los. Para isso, é preciso, desde cedo, incentivar meninas a se interessar pelos mais diversos assuntos, para que suas escolhas de carreira não sejam limitadas às opções tradicionais.

\section{REFERÊNCIAS}

CABRAL, Carla Giovana; BAZZO, Walter Antonio. As mulheres nas escolas de engenharia brasileiras: história, educação e futuro. Revista de Ensino de Engenharia, v. 24, n. 1, p. 3-9, 2005.

CUNHA, Luiz Antônio Constant Rodrigues da. O ensino de ofícios nos primórdios da industrialização. São Paulo: Editora UNESP, Brasília, DF: Flocos, 2000.

FERREIRA, Nilce Vieira Campos. . Economia Doméstica:ensino profissionalizante feminino no triângulo mineiro (Uberaba/MG - 1953-1997). Jundiaí: Pacto Editorial, 2014.

FIGUEIREDO. Luiz Carlos. O gênero na educação tecnológica: uma análise de relações de gênero na construção de habilidades e competências da Área de Construção Civil do Centro Federal de Educação Tecnológica de Mato Grosso. Dissertação de Mestrado. Campinas, SP 2008.

FONSECA, Celso Suckow da. História do ensino industrial no Brasil. Rio de Janeiro: Escola Técnica Nacional do Rio de Janeiro, 1961. v.1. 
KUNZE. Nádia Cuiabano. A Escola de Aprendizes Artífices de Mato Grosso 1909/1941. Cuiabá: EdUFMT; CEFETMT, 2006.

KUNZE. Nádia Cuiabano. A inserção da mulher na história do IFMT. In: SEMINÁRIO SOBRE GÊNERO NA HISTÓRIA DO MAGISTÉRIO DO ESTADO DE MATO GROSSO; ENCONTRO NACIONAL DE ESTUDOS DIRIGIDOS PARA MULHERES - ENEDIM, 3 ., 2009, Cuiabá. Cuiabá: IFMT; UNEMAT, nov. 2009. p. 1-5. (Palestra apresentada).

BRUSCHINI, C.; LOMBARDI, M. R.; UNBEHAUM, S. Trabalho, renda e políticas sociais: avanços e desafios. In: Fundo de desenvolvimento das nações unidas para a mulher. $\mathbf{O}$ Progresso das mulheres no Brasil. Brasília: Fundação Ford; Cepia, 2006. p.60- 93.

LOURO, Guacira Lopes e MEYER, Dagmar. A escolarização do doméstico. A construção de uma escola técnica feminina (1946-1970). Cadernos de Pesquisa. SãoPaulo, No 87. p.4557. Nov.1993.

MAGALHÃES, Justino Pereira de. Tecendo Nexos: história das instituições educativas. Bragança Paulista/SP: Editora Universitária São Francisco, 1999.

MEZZANO, Alicia Corvalénde.Lembranças pessoais memórias institucionais: para uma metodologia de questionamento histórico-institucional. In: BUTELMAN, Ida (Org)

Pensando as instituições: teorias e práticas em educação. Porto Alegre: Artmed. 1998.

PERROT, Michelle. Os excluídos da História: operários, mulheres e prisioneiros. 2 ed. Rio de Janeiro: Paz e Terra, 1992/1998.

PERROT, Michelle. Minha História das Mulheres.São Paulo: Contexto, 2007.

PERROT, Michelle. História das Mulheres no Ocidente. São Paulo, Afrontamento, 1991.

REIS, Fidélis. Homens e Problemas do Brasil. Rio de Janeiro, Editora José Olympio, 1962.

SIQUEIRA, Elizabeth Madureira. Luzes e sombras: Modernidade e educação pública em Mato Grosso (1870-1889). Cuiabá: EdUFMT, 2000.

SCHIEBINGER, Londa. Mais mulheres na ciência: questões de conhecimento. Apresentação de Maria Margaret Lopes. História, Ciências, Saúde - Manguinhos, Rio de Janeiro, v.15, supl., p.269-281, jun. 2008.

SOARES, Manoel Jesus. Uma Nova Ética do Trabalho nos Anos 20 - Projeto Fidelis Reis. Série Documental/Relatos de Pesquisa n. 33. Universidade Santa Úrsula, 1995.

\section{LEIS, DESPACHOS, DECRETOS E PORTARIAS}

BRASIL. Lei no 11.892, de 2008. Institui a Rede Federal de Educação Profissional, Científica e Tecnológica, cria os Institutos Federais de Educação, Ciência e Tecnologia, e dá outras providências. Brasília, 2008.

BRASIL. Lei $\mathbf{n}^{\circ} \mathbf{7 . 0 4 4}$ de 18 de outubro de 1982. Altera dispositivos da Lei $n^{\circ} 5.692$, de 11 de agosto de 1971, referentes a profissionalização do ensino de $2^{\circ}$ grau. Brasília, 1982.

BRASIL. Lei $\mathrm{n}^{\circ} 5.692$ de 11 de agosto de 1971. Fixa Diretrizes e Bases para o ensino de $1^{\circ} \mathrm{e}$ $2^{\circ}$ graus, e dá outras providências. Brasília, 1971. 
BRASIL. Instituto Federal de Educação, Ciência e Tecnologia de Mato Grosso. Relatório de Gestão do IFMT. 2017.

BRASIL. Decreto $\mathbf{n}^{\mathbf{0}} \mathbf{7 . 5 6 6}$, de 23 de setembro de 1909. Cria nas capitais dos Estados as Escolas de Aprendizes Artífices, para o ensino profissional primário e gratuito. De 23 de Setembro de 1909.

BRASIL. Decreto n ${ }^{\circ} 6.095$ de 24 de abril de 2007. Estabelece diretrizes para o processo de integração de instituições federais de educação tecnológica, para fins de constituição dos Institutos Federais de Educação, Ciência e Tecnologia - IFET, no âmbito da Rede Federal de Educação Tecnológica. Brasília, 2007.

BRASIL. Portaria No 862. DOU - 19 de abril de 2017. Brasília. 2017.

BRASIL. Portaria Nº 870. DOU -19 de abril de 2017. Brasília. 2017.

BRASIL. Portaria Nº 871. DOU -20 de abril de 2017. Brasília. 2017.

MATO GROSSO. SECRETARIA DE SERVIÇOS LEGISLATIVOS. 16/11/2016. Projeto de resolução no 302/2016. Protocolo no 4888/2016. Processo no 1019/2016. Concede título de cidadã mato-grossense a senhora Teresa Irene Ribeiro De Carvalho Malheiro. Autor: Dep. Dr. Leonardo. Plenário das Deliberações "Deputado Renê Barbour” em 11 de Novembro de 2016.

MATO GROSSO. Relatório da Gestão de Recursos Humanos - GDRH do CEFETMT. 2007

MATO GROSSO. Relatório da Gestão de Recursos Humanos - GDRH IFMT- 2008 a 2018.

\section{JORNAIS}

JORNAL ON LINE "OLHAR DIRETO". Edição do dia 29 de dezembro de 2009. Título "Um ano de vida: o IFMT escreve sua história". Cuiabá, 2009. Disponível em:

http://www.olhardireto.com.br/noticias/exibir.asp?id=72847\&noticia=um-ano-de-vida-o-ifmtescreve-sua-historia. Visitado em 13 de junho de 2018.

\section{SISTEMAS}

Assessoria de Comunicação do IFMT. 10/09/2014. Disponível em:

http://bag.antigoportal.ifmt.edu.br/noticias/1009687/. Acesso em 15 de junho de 2018.

Assessoria de Comunicação do IFMT. 16/01/2018. Disponível em:

http://ifmt.edu.br/conteudo/noticia/professora-do-ifmt-campus-bela-vista-e-selecionada-peloprograma-de-bolsa-produtividade-em-pesquisa-do-cnpq. Visitado em: 05 de junho de 2018.

Sistema Unificado de Administração Pública- SUAP, Junho de 2018. Disponível em: https://suap.ifmt.edu.br/accounts/login/?next=/. Visitado em: 08 de junho de 2018.

Recebido em: 17 de maio de 2020.

Aprovado em: 30 de agosto de 2020. 